\title{
Research Article \\ Effects of Adhesive Connection on Composite Action between FRP Bridge Deck and Steel Girder
}

\author{
Xu Jiang, ${ }^{1,2}$ Chengwei Luo, ${ }^{1}$ Xuhong Qiang, ${ }^{1,2}$ Henk Kolstein, ${ }^{2}$ and Frans Bijlaard ${ }^{2}$ \\ ${ }^{1}$ College of Civil Engineering, Tongji University, Shanghai 200092, China \\ ${ }^{2}$ Faculty of Civil Engineering and Geoscience, Delft University of Technology, 2628 CN Delft, Netherlands \\ Correspondence should be addressed to Xuhong Qiang; qiangxuhong@tongji.edu.cn
}

Received 21 November 2016; Accepted 19 February 2017; Published 16 March 2017

Academic Editor: Chiara Bedon

Copyright (c) $2017 \mathrm{Xu}$ Jiang et al. This is an open access article distributed under the Creative Commons Attribution License, which permits unrestricted use, distribution, and reproduction in any medium, provided the original work is properly cited.

\begin{abstract}
The FRP-steel girder composite bridge system is increasingly used in new constructions of bridges as well as rehabilitation of old bridges. However, the understanding of composite action between FRP decks and steel girders is limited and needs to be systematically investigated. In this paper, depending on the experimental investigations of FRP to steel girder system, the Finite Element (FE) models on experiments were developed and analyzed. Comparison between experiments and FE results indicated that the FE models were much stiffer for in-plane shear stiffness of the FRP deck panel. To modify the FE models, rotational spring elements were added between webs and flanges of FRP decks, to simulate the semirigid connections. Numerical analyses were also conducted on four-point bending experiments of FRP-steel composite girders. Good agreement between experimental results and FE analysis was achieved by comparing the load-deflection curves at midspan and contribution of composite action from FRP decks. With the validated FE models, the parametric studies were conducted on adhesively bonded connection between FRP decks and steel girders, which indicated that the loading transfer capacity of adhesive connection was not simply dependent on the shear modulus or thickness of adhesive layer but dominated by the in-plane shear stiffness $K$.
\end{abstract}

\section{Introduction}

Fiber-reinforced polymer (FRP) materials are increasingly being used in civil infrastructure applications. One conspicuous application of FRP composites is bridge decks (Figure 1), for the rehabilitation and new construction of pedestrian and highway bridges [1-3]. Due to the light weight of FRP bridge decks (about $10-20 \%$ of a reinforced concrete deck), the dead load can be substantially reduced, which leads to a significant saving for the structure and foundations. Meanwhile, the light weight decks can be rapidly installed with minimum traffic disruption. Comparing with the reinforcing steel, FRP composite materials possess a larger tolerance for frost and deicing salts. Consequently, longer service life and low maintenance costs are confirmed.

To be cost effective, most of the FRP decks need steel main girders to bridge the required spans. Steel girders enhance the ductility of this composite bridge system after failure loading achieved, which compensates for the brittle characteristics of FRP composites. Figure 2 shows the typical FRP composite to steel girder bridge system, which has already been utilized in the West Mill Bridge constructed in UK, 2002 [2], and the Friedberg road bridge constructed in Germany, 2008 [4]. The pultruded FRP composite decks are supported by the I-shape steel beams and in-between is adhesively bonded connection. Adhesive bonding technique is usually the excellent alternative for the connections between FRP decks and steel beams [5-7]. Comparing to bolted or stud connections, adhesively bonded connections can reduce construction time, save weight by eliminating fasteners, introduce more uniform load transfer, and provide better long-term performance.

To compete with concrete decks, in addition to the transverse load-carrying function, FRP bridge decks should also contribute as part of the top chords of the main girders in the longitudinal axis of the bridge. Particularly in the case of concrete deck replacement for rehabilitation of old bridges, FRP decks must be capable of maintaining the longitudinal top chord function; otherwise the main girders must be strengthened. It is evident that the FRP deck is not as stiff as a concrete deck in the longitudinal direction 


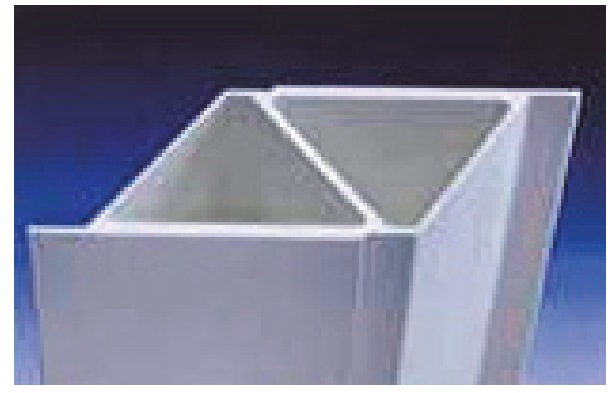

(a) ASSET (Fiberline, Denmark)

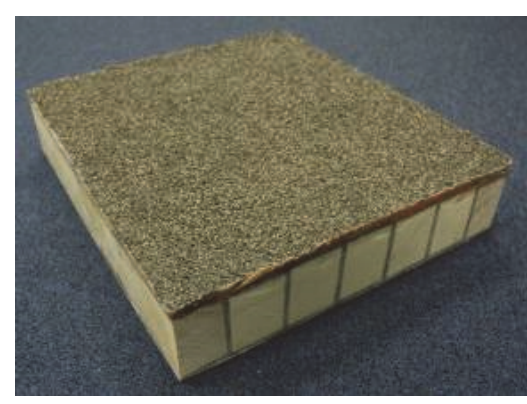

(b) ECOSAFE (Lightweight Structure, Netherlands)

FIGURE 1: FRP bridge decks.

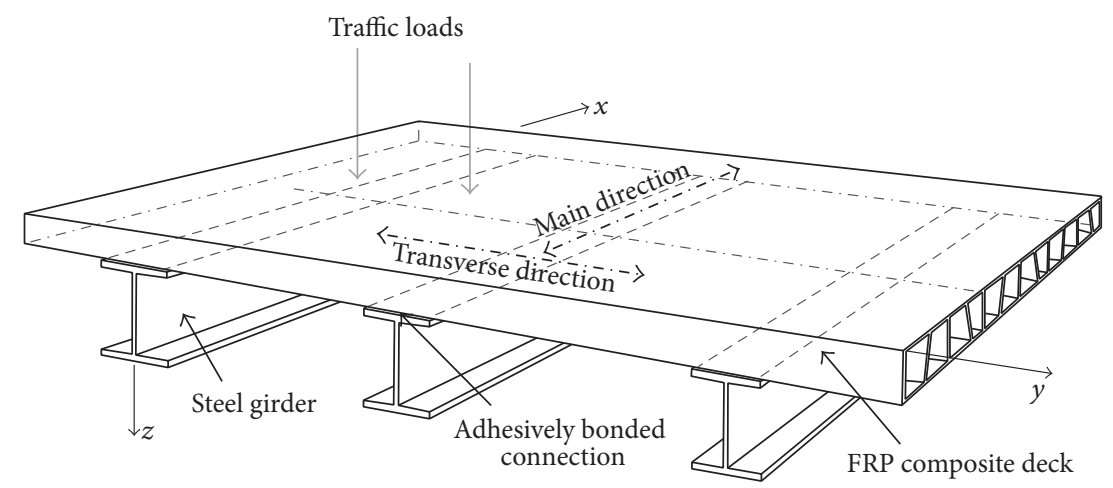

FIGURE 2: FRP composite to steel girder bridge system [6].

of bridges and will therefore contribute less to composite action between FRP decks and steel girders. In the case that the composite action between girders and FRP decks is not precisely understood, these two elements are often designed very conservatively with two limiting conditions: girders are designed without considering any composite action of the FRP deck, and calculations for the deck are made assuming full composite action [7]. Thus, it is of great importance to understand the degree of composite action between FRP decks and steel girders. As demonstrated in [7], the adhesively bonded connection between bridge decks and steel girders was sufficient to guarantee full load transfer between the top steel flanges and lower deck face panel. And the in-plane shear stiffness of FRP decks dominated the composite action degree of this composite girder system. This paper is the follow-up research on Gurtler's Ph.D. works [7].

The behaviors of FRP decks and FRP reinforced concrete structures have been studied through many theoretical and experimental investigations (Bottenberg, 2010 [8]; Pilakoutas et al., 2011 [9]). Optimum design of FRP rib core bridge deck was proposed by Dey et al., 2013 [10]. And an efficient lightweight design method of FRP bridge deck was developed by Dey et al., 2015 [11]. In this research, the Finite Element (FE) model was developed and modified based on the experimental studies. Subsequently, parametric studies on the loading transferring capacity of adhesively bonded connection were conducted by varying the modulus and thickness of the adhesive layer between FRP decks and steel girder.

\section{Numerical Modelling}

In Gurtler's research [7], the "in-plane" compression and shear experiments on FRP decks were conducted (Figure 3) to get the nominal compression modulus and nominal shear modulus of the whole FRP deck panel, which were used to develop the design methods for the FRP-steel composite girder system. Each specimen consists of two ASSET elements (Figure 4) adhesively bonded together with a twocomponent epoxy adhesive NM BPE Lim 465. The pultruded profile (produced by Fiberline Company) which builds the basis of specimens is shown in Figure 4. Pultruded glass-FRP profiles have E-glass fibers in form of roving bundles used as reinforcements in the middle. The direction of the roving fibers runs in the pultrusion direction. Additional glass fiber mats are used as the outside layers for shear resistance. The mats can be of chopped strand mats (CSM), woven mats, or their combinations. The typical cross-section of a $10 \mathrm{~mm}$ thick pultruded GFRP profile is shown in Figure 5. A polyester surface veil is often added for protection and surface finishing. Mechanical properties of the ASSET element are supplied by manufacture, as listed in Table 1, which will be used as the input of mechanical properties for FE models. More details about the experiments can be found in Gurtler's Ph.D. thesis [7].

The FE models were developed with shell elements in FE package ABAQUS 6.8. (Figure 6) and loading and boundary conditions are shown in Figure 7 . The adhesively bonded joints between ASSET elements can be modeled 


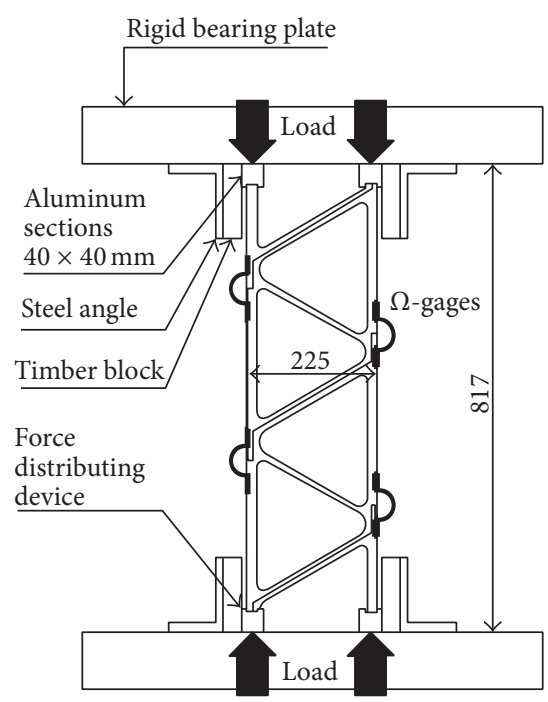

(a) Compression loading condition

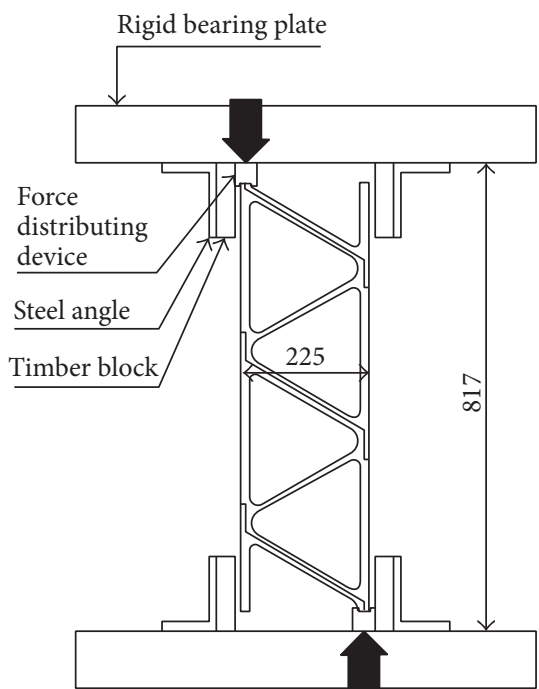

(b) Shear loading condition

FIGURE 3: Experimental investigation [7].

TABLE 1: Mechanical properties used for FEM modeling.

\begin{tabular}{lccc}
\hline Laminate properties & Face panels $(\mathrm{MPa})$ & Outer web $(\mathrm{MPa})$ & Inner web $(\mathrm{MPa})$ \\
\hline$E_{L}$ & 23000 & 17300 & 16500 \\
$E_{T}$ & 18000 & 22700 & 25600 \\
\hline
\end{tabular}

$E_{L}=E$ modulus in pultrusion direction; $E_{T}=E$ modulus across pultrusion direction.

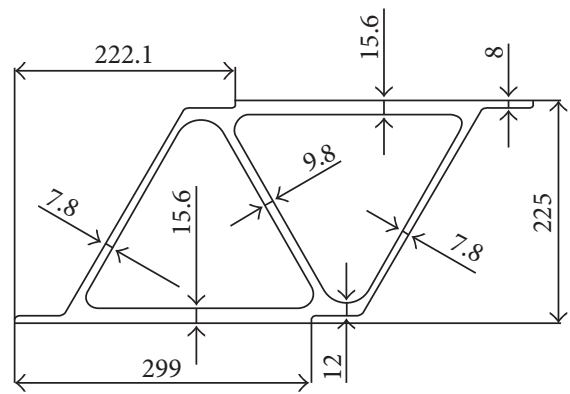

FIgURE 4: ASSET element.

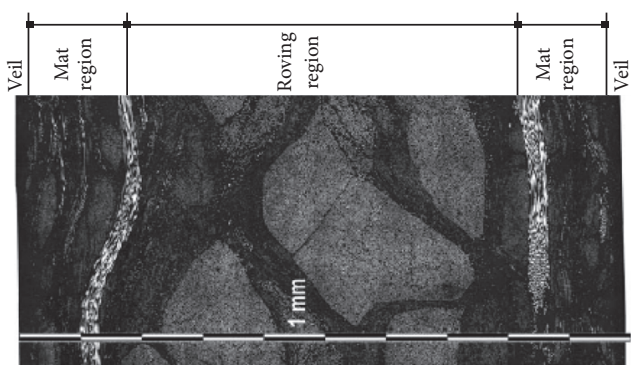

FIGURE 5: Cross-section of a $10 \mathrm{~mm}$ GFRP profile [5].

using composite layups, which involve one $7.8 \mathrm{~mm}$ thickness layup of outer web, one $1 \mathrm{~mm}$ thickness layup of adhesive, and again one $7.8 \mathrm{~mm}$ thickness layup of outer web. More

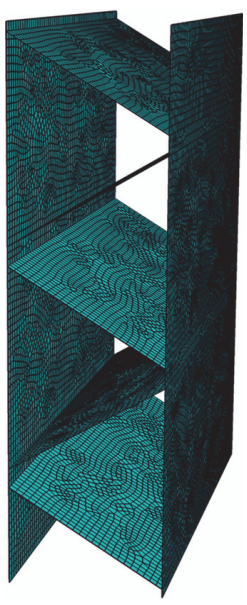

Figure 6: FE model.

details about composite layup commands can be found in Abaqus/CAE User's Manual. The whole FE analysis is linear elastic. Nonlinear material properties are not included.

Figure 8(a) presents the experimental results of loaddisplacement curves on the top of FRP deck specimens, comparing with FE analysis results, which implies an acceptable agreement between two curves under compression loading condition. Only the FE curve is slightly stiffer, while, for the shear loading condition, the differential displacements (shifts) between the deck face panels as a function of load are 


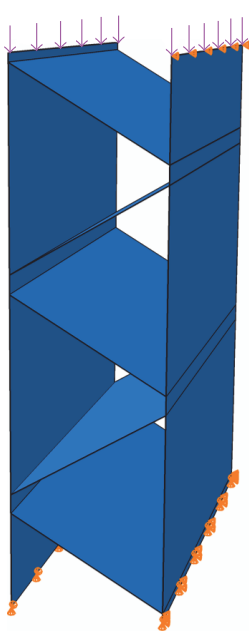

(a)

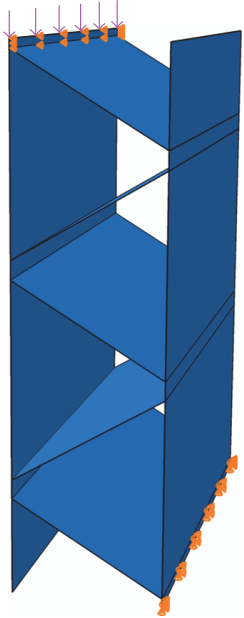

(b)

Figure 7: Loading condition (a: compression; b: shear).

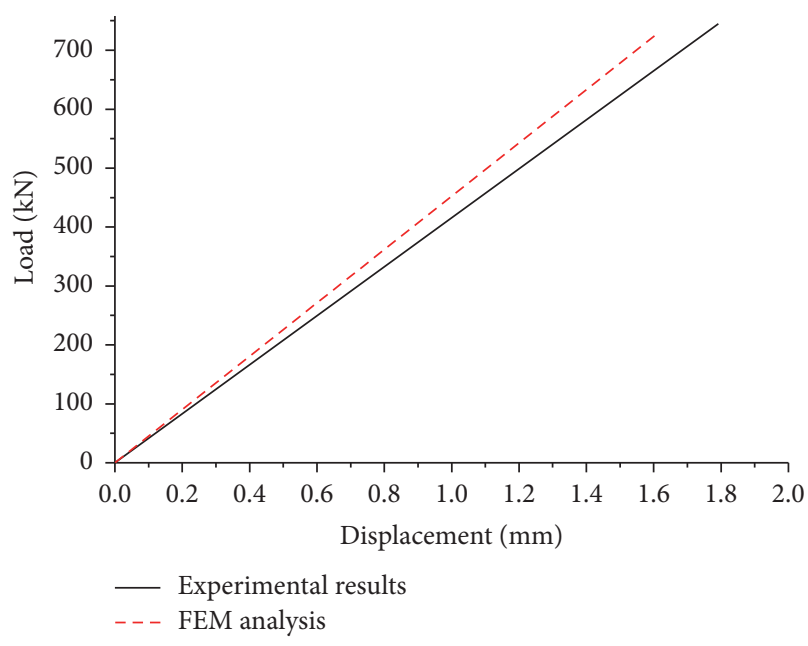

(a) Compression

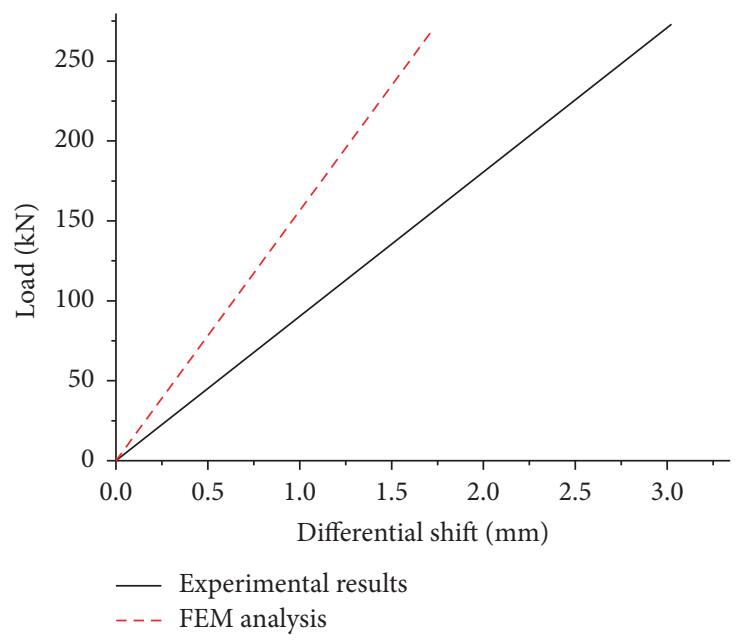

(b) Shear

FIGURE 8: Load-displacement curves.

shown in Figure 8(b). It is evident that a large discrepancy is observed between experimental results and FE analysis. The stiffness of FE model is much higher, which indicates that the FE model should be modified.

Further consideration on the deviation of $\mathrm{FE}$ results leads to the inference that the connection between webs and flanges in the ASSET element is not fully rigid. Semirigid connections result in the substantial decrease of in-plane shear modulus of FRP deck panels. But, for the compression loading condition, the modulus of flange panel dominates the compression stiffness of FRP deck but is not sensitively related to the semirigid connection. To modify the FE models, the rotational spring elements were added, connecting webs and flanges to simulate the semirigid connections. The stiffness of spring elements is determined by fitting the FE results to experimental results. Load-displacement curves from modified FE models are drawn in Figure 9, comparing with experimental results. Under both compression and shear loading conditions, two curves are much closer to each other, which means the FE models are sufficiently accurate.

To investigate the composite action behavior between FRP decks and steel girders, the full-scale four-point bending experiments were conducted by Gurtler [7]. It is a $7.5 \mathrm{~m}$ span single supported bridge structure (Figure 10). For the connection between FRP decks and steel girder, a twocomponent epoxy adhesive (SikaDur 330) was employed, whose properties are presented in Table 2. The thickness of adhesive layer was controlled to be $6 \sim 10 \mathrm{~mm}$ by spacers.

FE model was built with the same dimensions of experiments, as shown in Figure 11. All the structural components were modeled by shell element except for the adhesive layer between FRP decks and steel girder. Since, in the following parametric studies, the thickness of adhesive layer was one of the considerable factors to influence the composite action behaviors, four elements were built in the through-thickness direction, which were the 8-node linear solid elements. 


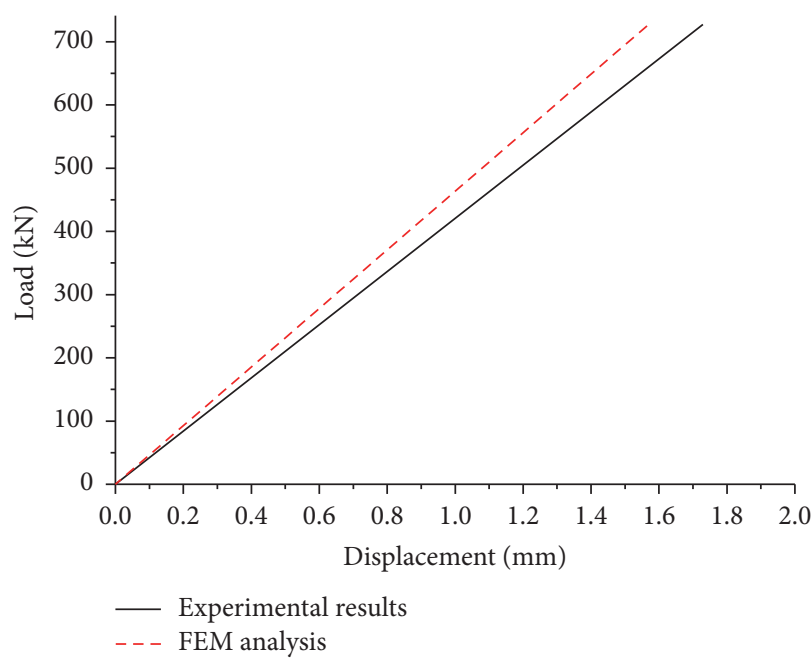

(a) Compression

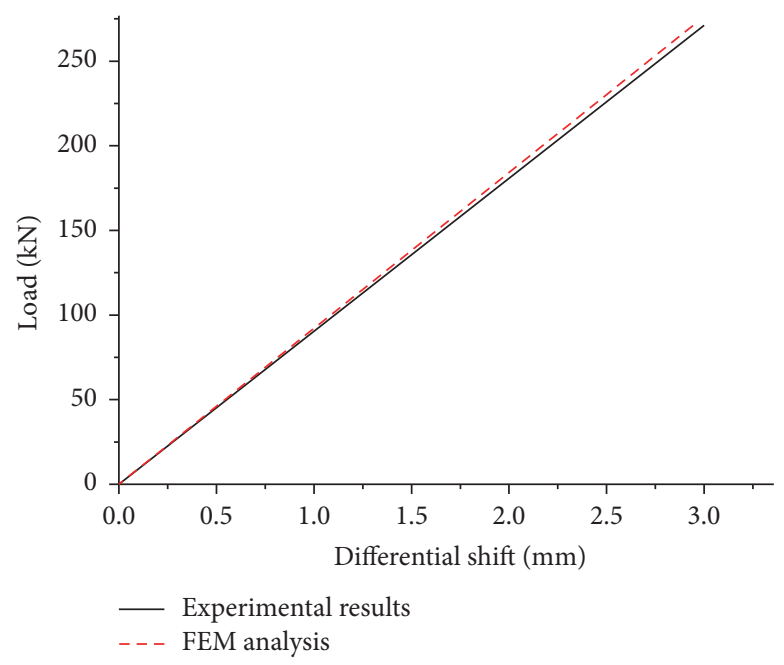

(b) Shear

FIGURE 9: Load-displacement curves from modified FE models.

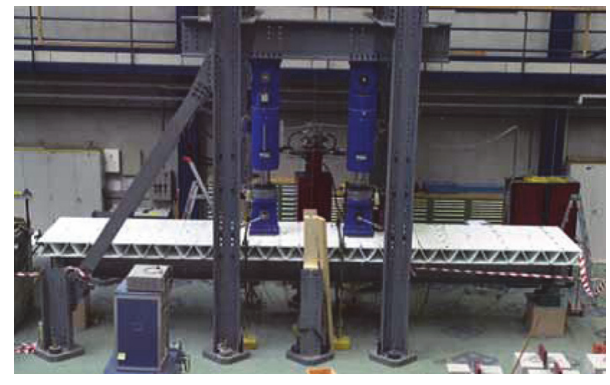

FIGURE 10: Four-point bending experiments on FRP-steel girder system [7].

TABLE 2: Material properties of SikaDur330.

\begin{tabular}{lc}
\hline Properties & SikaDur 330 \\
\hline Mixing ratio & $4: 1$ \\
Density $\left(\mathrm{kg} / \mathrm{m}^{3}\right)$ & 1310 \\
Viscosity @ $25^{\circ} \mathrm{C}$ & Thixotropic \\
Potlife @ $10^{\circ} \mathrm{C}$ & 90 minutes \\
Tensile strength $(\mathrm{MPa})$ & 30 \\
Bending $E$ modulus $(\mathrm{MPa})$ & 3800 \\
\hline
\end{tabular}

Comparing with shell elements, solid elements can deform in the through-thickness direction, which was much closer to the actual conditions of experiments.

Comparison of experimental and FE results are shown in Figures 12 and 13. Figure 12 presents the load-deflection curves at midspan. Good agreement is achieved between two curves, which means the stiffness of FE model is almost the same as experimental structures. Figure 13 shows the axial strain distribution at midspan section under $90 \mathrm{kN}$ loading per jack. It is found that axial strain distributions across the steel section from experimental and FE results superpose each other, which means the contributions of composite

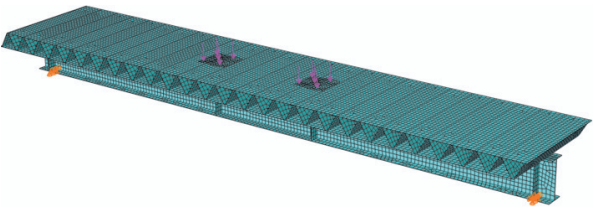

FIGURE 11: FE model of FRP-steel girder system.

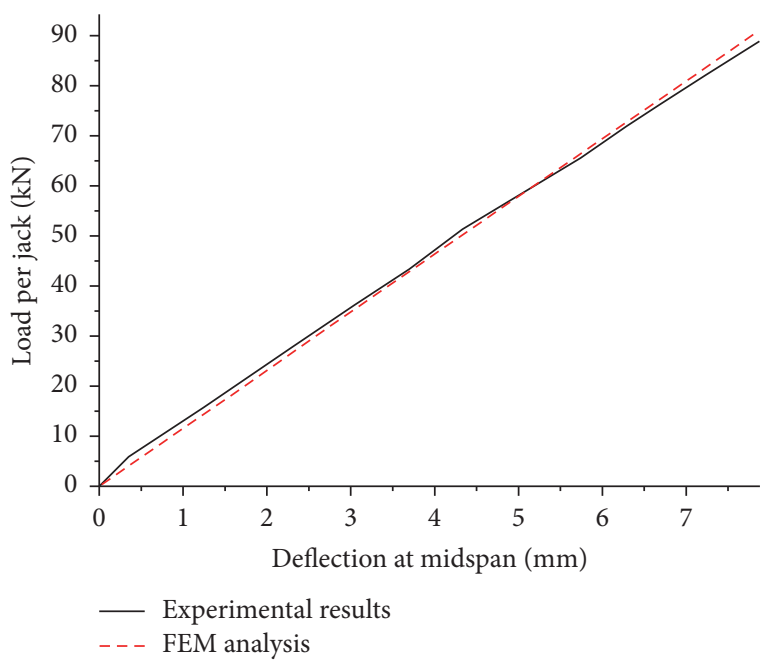

FIGURE 12: Deflection at midspan.

action from FRP decks are equivalent. Full loading transfer capacity is obviously achieved in the adhesive connection between decks and girders. But, for the axial strain on the top flange of FRP decks, deviations are found between two curves. It can be attributed to the fact that, from Figure 3, the semirigid stiffness of connection between inner webs and flanges should be different from the connection between outer webs and flanges. But, in the FE model, all the semirigid 
TABLE 3: Results of the parametric study.

\begin{tabular}{|c|c|c|c|c|}
\hline & Shear modulus (MPa) & Thickness (mm) & Shear modulus $K(\mathrm{MPa} / \mathrm{mm})$ & Neutral axis $(\mathrm{mm})$ \\
\hline Experiment & 1407 & 8 & 176 & 326.5 \\
\hline \multirow{7}{*}{ FEM } & 1407 & 8 & 176 & 319.6 \\
\hline & 40 & 8 & 5.0 & 315.5 \\
\hline & 16 & 16 & 1.0 & 293.1 \\
\hline & 8 & 8 & 1.0 & 294.0 \\
\hline & 6.4 & 16 & 0.4 & 280.2 \\
\hline & 3.2 & 8 & 0.4 & 280.4 \\
\hline & 1.6 & 8 & 0.2 & 267.4 \\
\hline
\end{tabular}

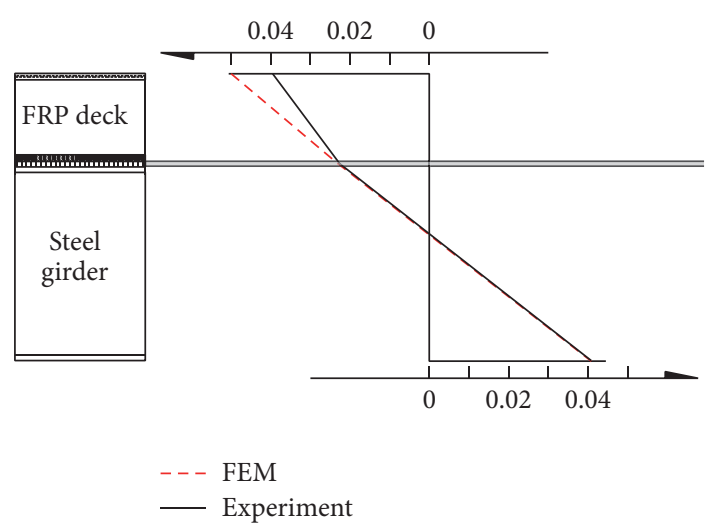

FIGURE 13: Axial strain (\%) at midspan section under SLS loads (90 kN/jack).

stiffness of rotational spring elements is the same, since the experimental data is too limited to offer the separated spring stiffness values. Thus, the loading transfer capacity for each connection between webs and flanges of FRP decks is not identical in experiments, but it is identical for FE models. Therefore, deviations occur between experimental and FE results for the axial strain at the midspan section. Based on the above discussion, it can be confirmed that the FE models are well built and sufficiently accurate for the parametric study.

\section{Parametric Study}

The parametric study was focusing on the adhesively bonded connection. By varying the modulus and thickness of adhesive layer, the degree of composite action of FRP-steel girder system was investigated. Depending on Gurtler's research [7], the in-plane shear stiffness $K$ dominated the load transfer capacity of adhesive layer. $K$ is represented as follows:

$$
K=\frac{G}{t},
$$

where $G$ is the shear modulus of adhesive material and $t$ is the thickness of adhesive layer. with $E$ modulus $=3800 \mathrm{MPa}$ and Poisson ratio $v=0.35$, the shear modulus $G$ of SikaDur 330 adhesive used in four-point bending experiments is determined as follows:

$$
G=\frac{E}{2(1+\nu)}=1407 \mathrm{MPa} .
$$

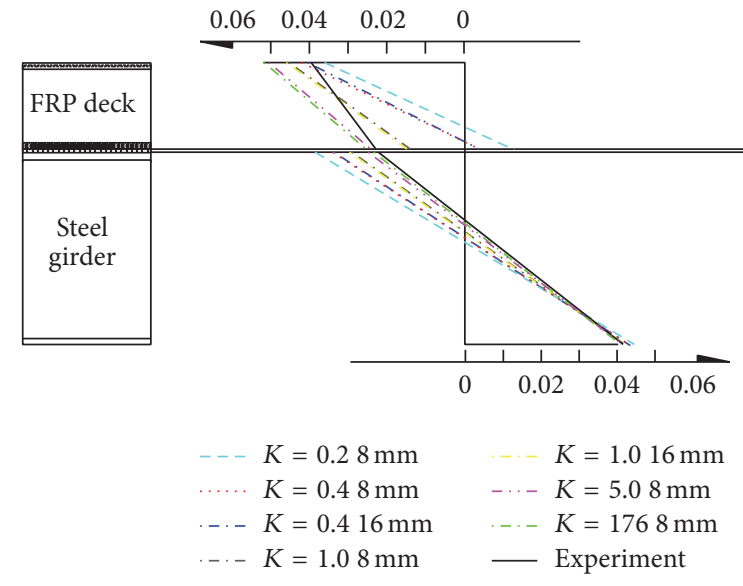

FIgURE 14: Axial strain distributions at midspan section from the parametric study.

Several values of in-plane shear stiffness $K$ were selected for the parametric study, comparing with the experiments. The thickness of adhesive layer was proposed to be $8 \mathrm{~mm}$ and $16 \mathrm{~mm}$. Correspondingly, the shear modulus of adhesives was calculated by (1), as listed in Table 3 .

Results of the parametric study are shown in Figure 14 and Table 3. The location of neutral axis is calculated from the bottom of the steel I-shape beam. The height of beam is $500 \mathrm{~mm}$. Thus, neutral axis of composite girder with no contribution of composite action from FRP decks is $250 \mathrm{~mm}$. The experimental results are also involved as reference values. Figure 14 shows the axial strain variation across the midspan section with different values of in-plane shear modulus $K$. It can be found that the strain distribution and locations of neutral axis from curves of $K=5 \mathrm{MPa} / \mathrm{mm}$ and $K=$ $176 \mathrm{MPa} / \mathrm{mm}$ are almost identical to each other, which means even an extremely low shear modulus of adhesive layer can still offer the full load transfer capacity for this type of FRP decks. This indicates that there is no need for adhesive to be so stiff. Some other flexible adhesives can be a good alternative, because due to different thermal expansion coefficients of FRP decks and steel girders, thermal cycling during seasons will result in cracks through brittle adhesive connections. Flexible adhesives with the large failure strain provide a good resistance for thermal cracks. From Figure 14 and Table 3, further parametric study indicates that the strain distribution 
and location of neutral axis are not simply dependent on the shear modulus or thickness of adhesive layer but dominated by the in-plane shear stiffness $K$ of adhesive layer. The adhesive layer with different modulus and thickness can result in almost the same loading transfer capacity. For instance, the curves from $K=1.0 \mathrm{MPa} / \mathrm{mm}$ are much closer to each other, as well as curves from $K=0.4 \mathrm{MPa} / \mathrm{mm}$. It is also a fact that if the values of $K$ are lower than a certain value, it will result in decrease of composite action degree and correspondingly the neutral axis will move down. The bottom of FRP decks is under tension for the cases of $K=0.4 \mathrm{MPa} / \mathrm{mm}$ and $K=0.2 \mathrm{MPa} / \mathrm{mm}$. However, even a small $K$ value of $0.2 \mathrm{MPa} / \mathrm{mm}$ can still offer a considerable load transfer capacity, with the neutral axis $16.4 \mathrm{~mm}$ higher than that of the single steel beam with no composite action. For most of commercial available adhesives in the market and realistic adhesive thickness for applications in composite bridges, their in-plane shear stiffness $K$ s are enough to achieve the full load transfer capacity of the adhesive layer.

\section{Conclusions}

Depending on the experimental investigation from Gurtler's research [7], the FE models on experiments were developed and analyzed. Comparison with experimental results indicated that the FE models were much stiffer for in-plane shear stiffness of the FRP deck panel. To modify the FE models, rotational spring elements were added between webs and flanges of FRP decks, to simulate the semirigid connections. Numerical analysis was also conducted on four-point bending experiments of FRP-steel composite girders. Good agreement between experimental results and FE analysis was achieved by comparing the load-deflection curves at midspan and contribution of composite action from FRP decks. With the validated FE models, the parametric studies were conducted on adhesively bonded connection between FRP decks and steel girders. The conclusions can be drawn that the loading transfer capacity of adhesive connection was not simply dependent on the shear modulus or thickness of adhesive layer but dominated by the in-plane shear stiffness $K$. The adhesive connection with $K$ equal to $5 \mathrm{MPa} / \mathrm{mm}$ was sufficient to offer the full loading transfer capacity. Thus the in-plane shear stiffness $K$ should be regarded as the main factor while designing adhesively bonded connections. And a small $K$ value of $0.2 \mathrm{MPa} / \mathrm{mm}$ can still offer a considerable load transfer capacity, which indicates a specific safety range of $K$ in practical engineering. The research of this paper can lead to a better understanding of composite action between FRP decks and steel girders as well as smart selections on mechanical properties and thickness of adhesively bonded connections.

\section{Conflicts of Interest}

The authors declare that they have no conflicts of interest.

\section{Acknowledgments}

The authors would like to thank the National Natural Science Foundation of China (Program no. 51408424) and the
Fundamental Research Funds for the Central Universities for financial support of this research.

\section{References}

[1] T. Keller, Y. Bai, and T. Valle, "Long-term performance of a glass fiber-reinforced polymer truss bridge," Journal of Composites for Construction, vol. 11, no. 1, pp. 99-108, 2007.

[2] S. Luke, L. Canning, S. Collins et al., "Advanced composite bridge decking system-project ASSET," Structural Engineering International, vol. 12, no. 2, pp. 76-79, 2002.

[3] S. Alampalli and J. Kunin, "Rehabilitation and field testing of an FRP bridge deck on a truss bridge," Composite Structures, vol. 57, no. 1-4, pp. 373-375, 2002.

[4] J. Knippers, E. Pelke, M. Gabler, and D. Berger, "Bridges with glass fibre-reinforced polymer decks: the road bridge in Friedberg, Germany," Structural Engineering International: Journal of the International Association for Bridge and Structural Engineering (IABSE), vol. 20, no. 4, pp. 400-404, 2010.

[5] A. Zhou and T. Keller, "Joining techniques for fiber reinforced polymer composite bridge deck systems," Composite Structures, vol. 69, no. 3, pp. 336-345, 2005.

[6] M. Schollmayer, Through-thickness performance of adhesive connections between FRP bridge decks and steel main girders [Ph.D. thesis], Ecole Polytechnique Federale de Lausanne, Lausanne, Switzerland, 2009.

[7] H. W. Gurtler, Composite action of FRP bridge decks adhesively bonded to steel main girders [Ph.D. thesis], Ecole Polytechnique Federale de Lausanne, Lausanne, Switzerland, 2004.

[8] R. D. Bottenberg, "Fiber-reinforced polymer decks for movable bridges," Structural Engineering International, vol. 20, no. 4, pp. 418-422, 2010

[9] K. Pilakoutas, M. Guadagnini, K. Neocleous, and S. Matthys, "Design guidelines for FRP reinforced concrete structures," Proceedings of the Institution of Civil Engineers: Structures and Buildings, vol. 164, no. 4, pp. 255-263, 2011.

[10] T. K. Dey, I. Srivastava, R. P. Khandelwal, U. K. Sharma, and A. Chakrabarti, "Optimum design of FRP rib core bridge deck," Composites Part B: Engineering, vol. 45, no. 1, pp. 930-938, 2013.

[11] T. K. Dey, T. Mukhopadhyay, A. Chakrabarti, and U. K. Sharma, "Efficient lightweight design of FRP bridge deck," Proceedings of the Institution of Civil Engineers-Structures and Buildings, vol. 168, no. 10, pp. 697-707, 2015. 


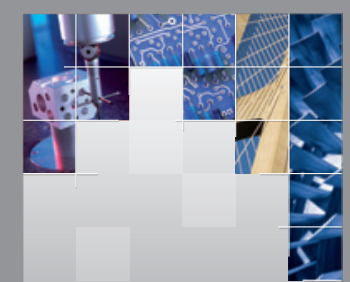

\section{Enfincering}
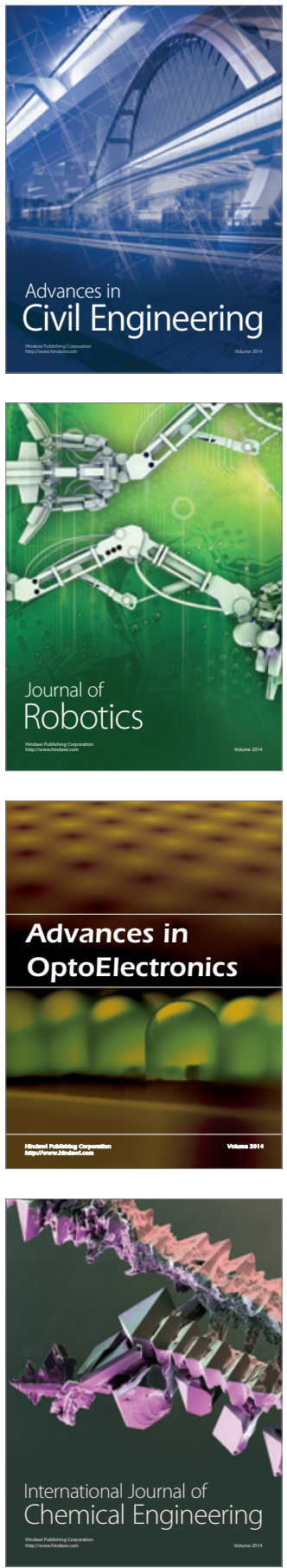

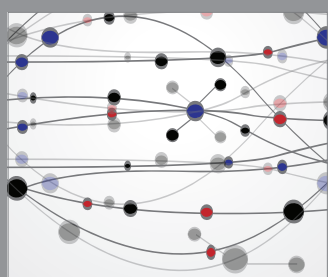

The Scientific World Journal

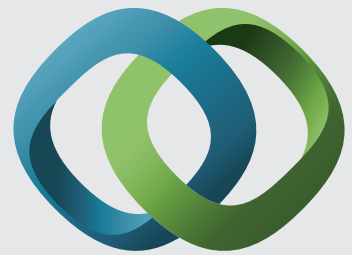

\section{Hindawi}

Submit your manuscripts at

https://www.hindawi.com
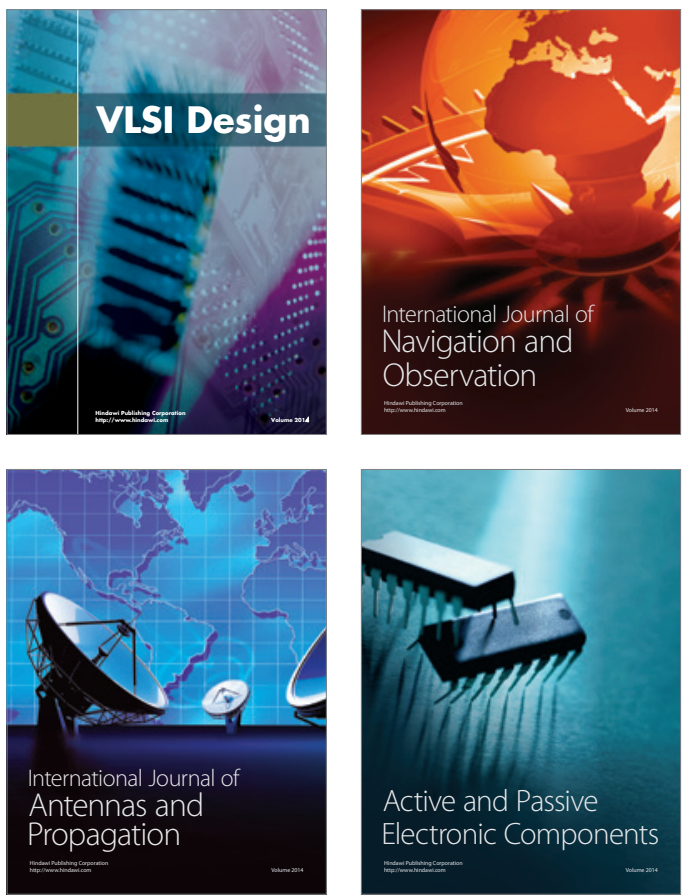
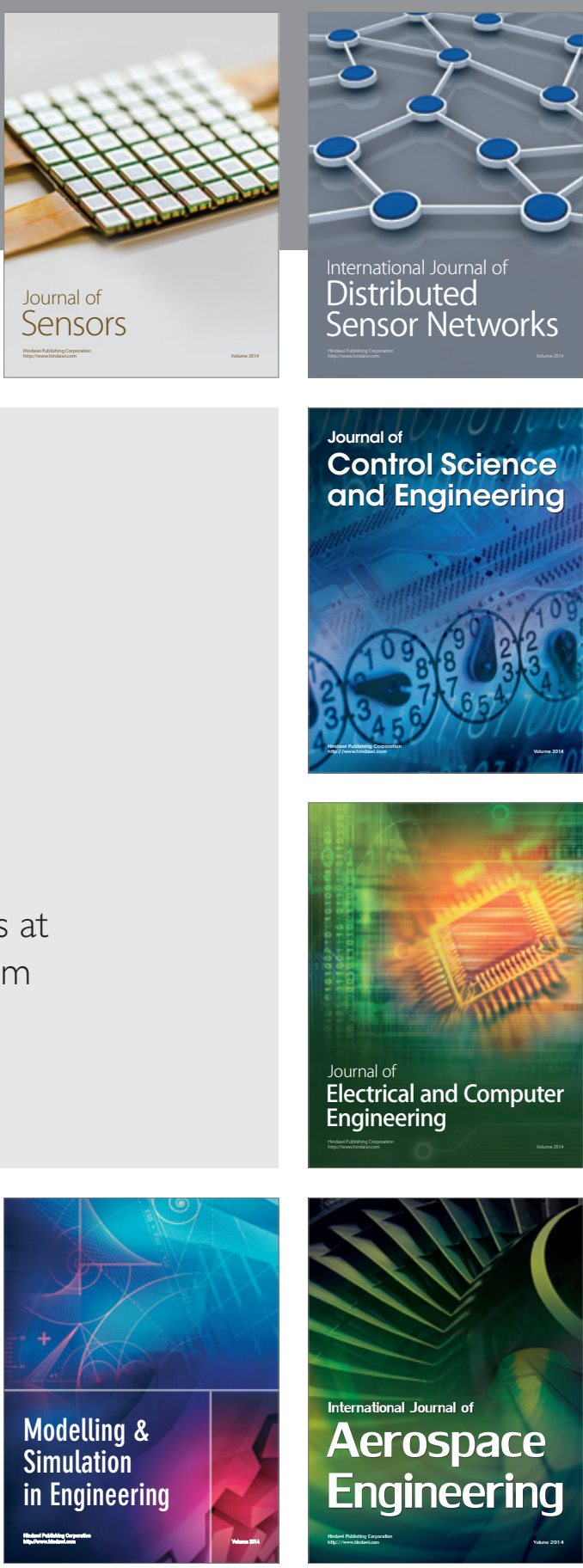

International Journal of

Distributed

Sensor Networks

$-$

Joumal of

Control Science

and Engineering
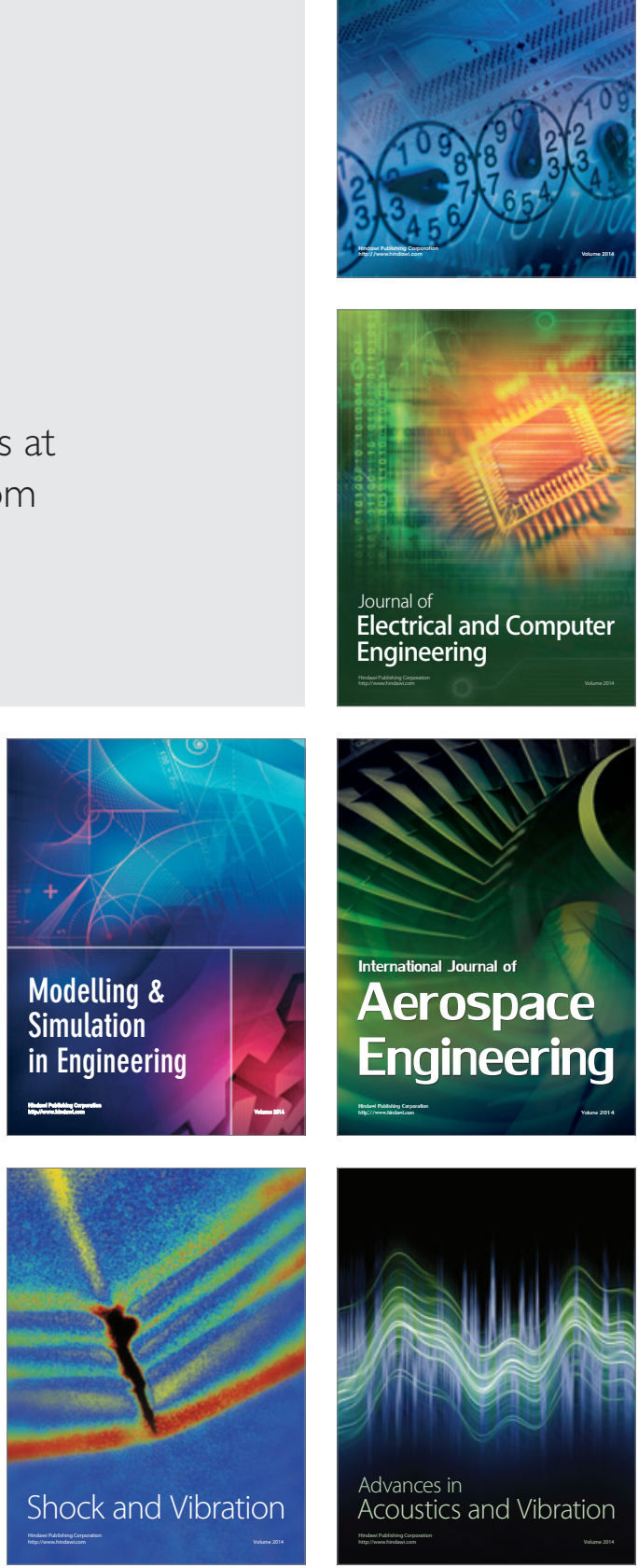